\title{
Selection of Unmanned Aerial Vehicle for Precision Agriculture with Multi-criteria Decision Making Algorithm
}

\author{
Imre Petkovics ${ }^{1}$, János Simon ${ }^{2}$, Ármin Petkovics ${ }^{3}$, Zlatko Čović ${ }^{2}$ \\ ${ }^{1}$ The Faculty of Economics Subotica, University of Novi Sad, Subotica, Serbia \\ ${ }^{2}$ Subotica Tech - College of Applied Sciences, Subotica, Serbia \\ ${ }^{3}$ Budapest University of Technology and Economics, Budapest, Hungary \\ E-mail: simon@vts.su.ac.rs, peti@ef.uns.ac.rs, peti@vts.su.ac.rs, petkovics@hit.bme.hu, chole@vts.su.ac.rs
}

\begin{abstract}
- the paper briefly describes the specifics of precision agriculture from the point of view of data needs and the possibility of providing such data. It points to the most convenient and efficient form of collecting the necessary data using drones. Specific drone characteristics are recorded/discussed in order to facilitate selecting the right one according to the farmers' heterogeneous requirements regarding the data collection on their crops. Selecting the appropriate drone for the specific needs of farmers is carried out by a multi-criteria decision-making software.
\end{abstract}

Keywords - Internet of Things, UAV

\section{INTRODUCTION}

Precision agriculture is a new way of farm management, which is based on observation, measurement and response to internal changes (illnesses, lack of nutrients and water) and / or external (drought, insects, rodents, wild animals) parameters related to crops. The main objective of this management approach is to use more the limited resources of farms efficiently (so as to reduce the costs of agricultural production) while also maximizing the yield [38]. The basic method for achieving this goal is to minimize any changes in plants, i.e. maintaining the health of crops. For the implementation of activities in precision agriculture it is necessary to provide a considerable amount of data ([44], [46], [50]) that can be classified as follows:

- Geo-tagged images: various types of images / pictures (visible and multi-spectral images) of crops during the growing season (this task can be performed by drones),

- Equipment data: the actual data from devices that have sensors (seeders, tractors, spreaders, harvesters, etc.),

- Data management: crop yield and other data provided by farm operators ([38], [39], [43]).

There are two alternatives for the implementation of surveillance / monitoring in modern agriculture:

- Network of intelligent sensors (Internet of Things),

- Unmanned Aerial Vehicles (UAVs) or Drones.

UAVs (Figure 1 [40]) have the ability of recording and analyzing the current or subsequent images in order to provide the same information as IoT devices. Drones offer another, new alternative in the collection of data for monitoring crop development and other indicators. The main advantage of alternatives related to drones is that the next recording sheet drone cameras can also collect data from a static set of intelligent IoT devices (in which case they do not have to be connected to the Internet) overflight of the territory.

\section{DISCUSSION}

The role of information technology is outstanding on sustainable development [52]. IoT application in agriculture is a modern solution based on the latest achievements in communications, computing (internet, cloud computing, big data and BI business intelligence) and sensory technology (intelligent sensors and actuators). Recently, IoT has been more intensely explored, and the possibilities of application and specific solutions are all much more numerous in agriculture ([1], [2], [3], [48]).

Using a network of intelligent sensors provides undeniable advantages such as modularity (installation of a new IoT devices in the network), robustness / fault tolerance (loss of the sensor does not disturb the operation of the network), flexibility (sensor network has a fixed architecture) and low power consumption / low power consumption (all devices in the network architecture). Using a network of IoT devices has still not become standard practice in the agro-industrial context, specific solutions have emerged only in small
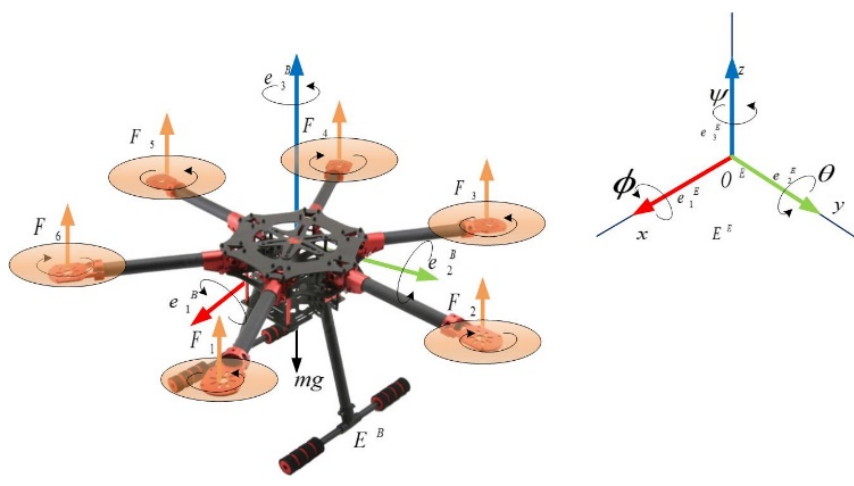

Figure 1. • Unmanned Aerial Vehicle (UAV) 
experimental areas and greenhouses. The most common reasons for the limited application of the IoT network is the fixed location, and therefore a large number of sensors, which entails high investment costs, particularly in larger areas. The suggestions for replacing the network of the intelligent sensors provided in greenhouses include mobile robots ([3]) and drones ([35], [45], [47]). For the collection and analysis of data in closed space the only alternative for IoT networks would be UAVs. These devices can be used for the treatment of agricultural fields as well).

The emergence of the drones dates back prior to the appearance of IoT devices. The first drones were applied for military purposes and therefore were robust, high speed, large capacity, using classical or jet drive. Soon, however, completely different UAV devices appeared on the scene: brittle, lightweight, and relatively slow on battery / electric drive. These newer drones were primarily intended for the civilian population as hobby devices or as a means to facilitate the work, perform acceleration and precise tasks in different areas of the economy, especially in agriculture. The advantages of using drones instead of IoT devices have been increasing recognized recently: they do not need to be set up with or have installed a large number of smart sensors in order to monitor their work, repair / replace IoT devices that are defective and provide internet for online transmission of the data collected. On the other hand, the solution using a drone is flexible (it can be applied to large areas of agricultural fields that can be dynamically changed for different types of dynamically varying tasks), and the investment is relatively solid (the price of the drone is continuously decreasing).

Today, a large scale of drone types (around 150) is used around the world, produced by many different manufacturers (55) in 18 countries, primarily from the USA and China (Figure 2 [40]). A relatively low percentage (11\%) of today's drones is used in agriculture, which puts this application area into fifth place behind Film \& Photography, Inspection / Mapping \& Surveying, Public Safety and Recreation / Hobby (Figure 3 [40]).

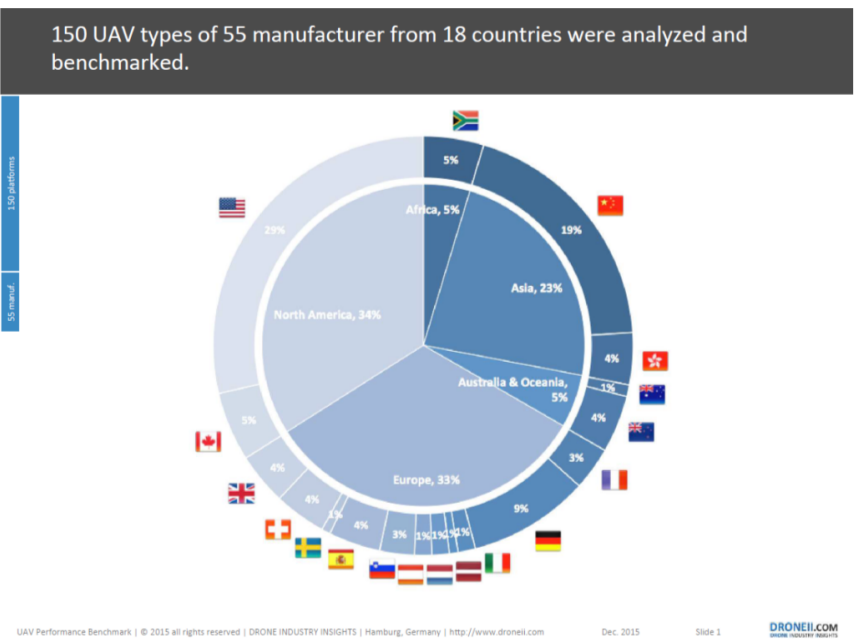

Figure 2. UAV manufacturers in countries
The examined platforms show a variety of possible applications and cover all current industry segments.

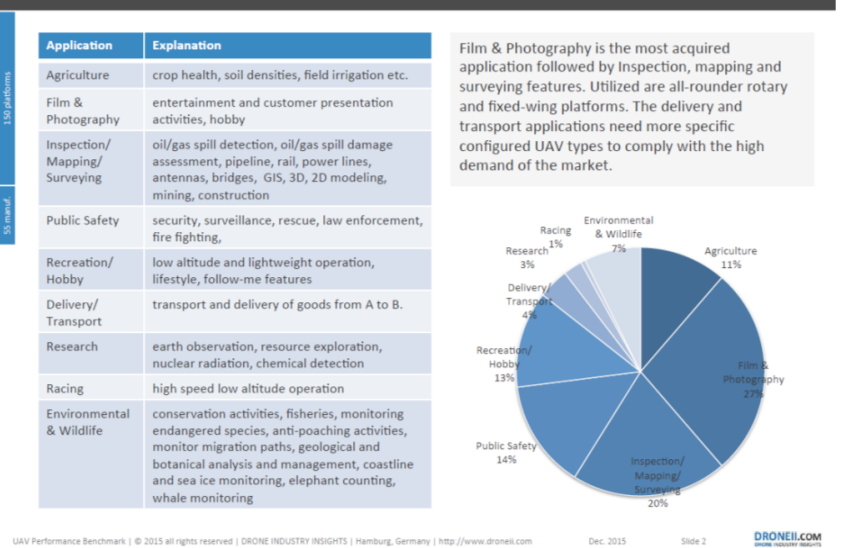

Figure 3. Percentage statement drones for various purposes with applications

In the next five years, however, it is expected that the agrarian field of implementation will show the largest increase in the number of UAV's. Among the producers, there are famous well-established names, such as Lockheed Martin, but the start-up companies, including Xcraft and Yuneec provide the majority. These companies risen through the ranks thanks to donations and foreign investors. Major investments and acquisitions in start-up companies in the field of drone technology from 2011 until today indicate that in addition to companies from the field of drone technology are also interested in companies outside of this segment to invest, integrate or buy promising, innovative, new ventures incubator (Figure 4 [41]).

Leading hardware and software manufacturers of the drone industry are shown in Figure. 5 [42]. It is based on the number of hits for a Google search, the number of news items and the number of employees in the dronemanufacturing company.

In terms of classification, the first important and obvious categorization of UAVs is based on how flight is achieved:

- UAV with fixed wings,

- Multi-rotor drones.

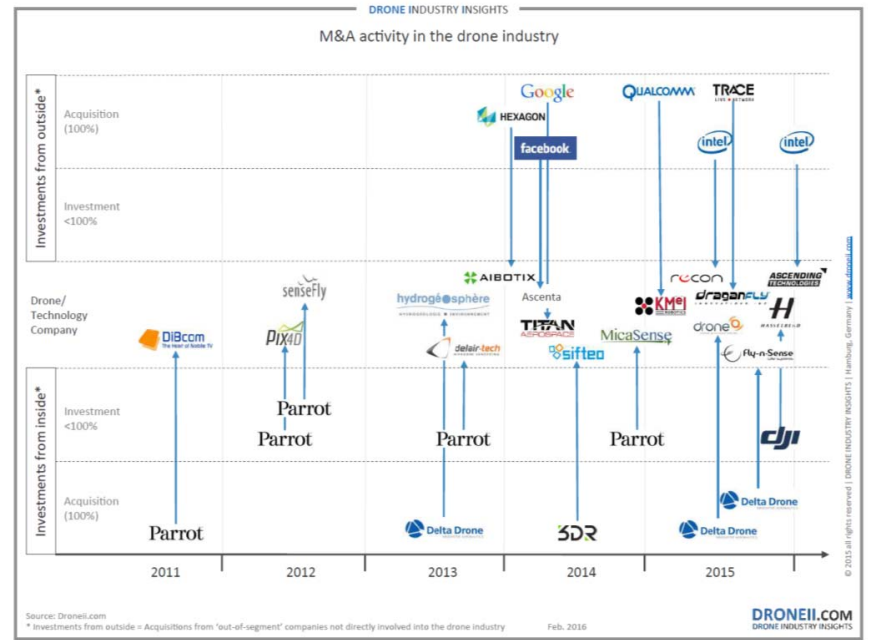

Figure 4. Major investments and acquisitions since 2011 


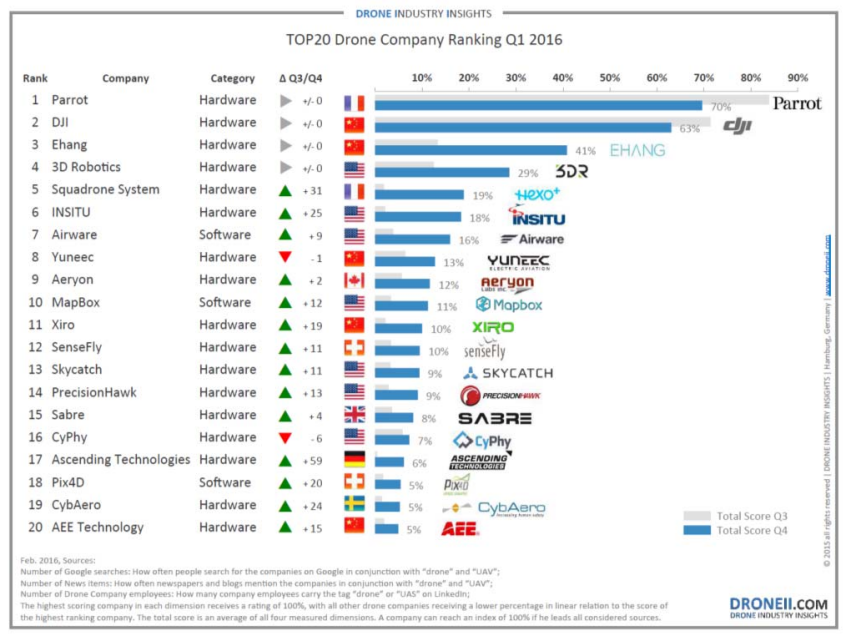

Figure 5. Ranking companies in the drone industry

In 2016, a hybrid drone appeared which, in one mode, may be floating in a single point as copter, and in a second mode can operate as a drone aircraft-with fixed wings [28]. The drive of the UAV is usually electric, although there are also some petrol-driven models. Fig. 6 [40] indicates the length of the flight in minutes, range, drive type, and payload for each section of the drone without indicating the model name.

Further, drones can be classified according to computational power (hardware) and intelligence (software) and can be categorized based on their weight. The top 10 drones are listed in three weight classes in Figure 7 [40].

\section{UAV-S IN AGRICULTURE}

Agriculture is a specific area regarding the application of drones, because of its complex set of requirements: UAV flight time should be as long as possible; the speed should be as high as possible so that they can cover the largest area possible. Conversely, the drone should also be able to float and carry as much payload as possible (due to the greater number of sensors), and it ought to have a powerful on-board computer (flight control and image processing and other data from sensors). Longer flight and higher speeds require greater battery power, which however, may come at the cost of the possible number of sensors or quantities of

\section{The graph shows UAV category and energy source in a grid of range and} endurance.

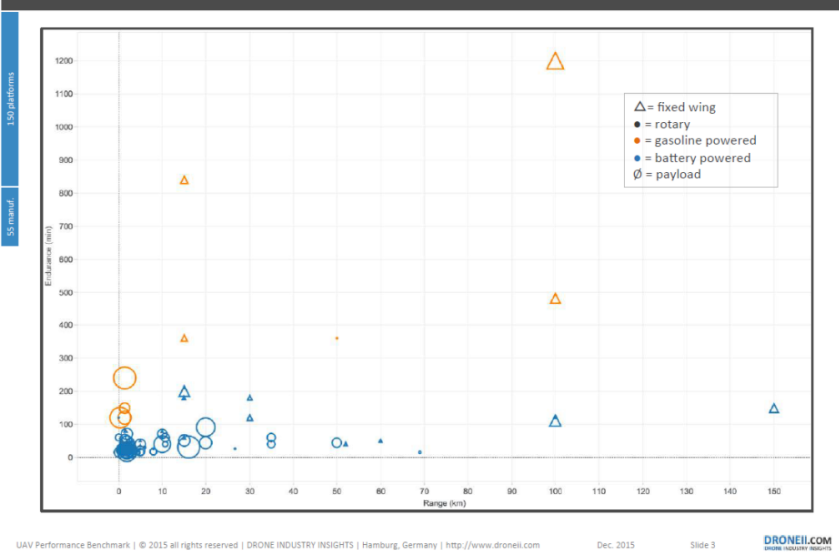

Figure 6. Time of flight, operation, range and payload of UAV-s pesticides / nutrients / mineral fertilizers. A more powerful on-board computer is an additional burden to the drone in terms of mass, which reduces the amount of payload. Because of the afore-mentioned contradictory requirements, numerous different drone models appeared which can fulfil different ones of these requirements, so one should combine the usage of these models carefully based on the models' characteristics. More specifically, some of the models will have greater coverage, while others can carry more payload, so they can jointly carry out all the tasks. Figure 6 presents the categorization of today's drones from the perspectives of coverage area and operational time.

Two drone types were introduced for data-collection in agriculture:

- UAAV - Unmanned Autonomous Aerial Vehicles,

- Radio-controlled UAV.

Both classes of drones are suitable for data collection: storing images of ordinary and special cameras, the recording of data from a variety of on-board or on the sensors located on the agricultural fields. The advantage of UAAV is in the autonomy of the performance of duties as well as the range/ time of flight. By rule this class of drones often has built-in, on-board artificial intelligence to detect and bypass obstacles, like pylons, wind turbines / wind farms on its itinerary. They can adapt to changing conditions, according to the speed and direction of the wind. UAAV is more reliable and has a much lesser degree of error.

Planes with fixed wings generally have a higher working speed and, thanks to larger batteries, can spend more time in the air from the copter. They also have higher loading capacity, i.e. they can carry a greater number of sensors. In short, they are intended for farms with large acreage, they can collect more diverse data in a shorter time period than a copter or multi copter.

Drone-planes have route-planning software with flight route definitions, as well as flight control based on GPS navigation. Their price is set accordingly, which is significantly higher than a copter. These models of UAV require quite a large space for landing (the runway must be $20 \mathrm{~m} \times 50 \mathrm{~m}$ in dimensions), and some models also have a ramp for takeoff. The most prominent manufacturers of drone-aircraft are AgEagle, Delair-Tech, PrecisionHawk, SenseFly and Honeycomb.

UAV will soon be categorized by application and weight class. To provide the current state of the art we created a ranking for each weight class up to $25 \mathrm{~kg}$.

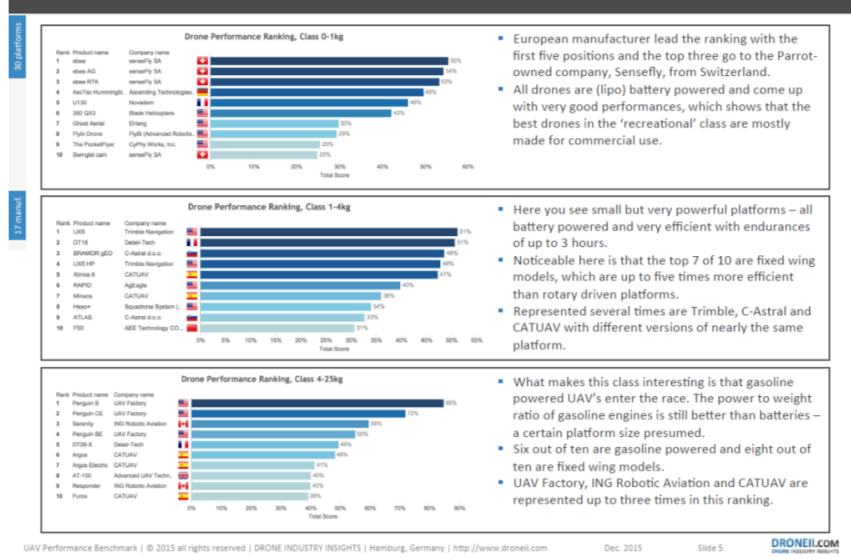

Figure 7. Ranking drones per weight category 
Copters / multi-rotor drones fly at a slower speed and can remain mid-air on average half as long as aircraft-drones. Their capacity (payload, referring to the payload) is smaller, therefore they can carry only two or three sensors. For this reason, collecting the desired data may take twice as long as with fixed-wing drones with. Further, copters do not need a runway for takeoff, and they can hover over one item, as opposed to drone-aircraft. They are designed for small, limited and less accessible areas. It must be also mentioned that copters are generally significantly cheaper than the drone-aircraft. Some farmers and almost all operators for crop-supervision have the tendency to buy both types of drones. It is suggested that for large parcels with long rectilinear passages without obstacles drones-planes should be used, whereas for spot-checking of the problematic areas on small parcels with many obstacles, or for uneven terrain conditions, copters are the optimal choice.

\section{OPTIMAL DRONE CHOICE FOR PRECISSION AGRICULTURE}

Over our research phase, we collected and systematized the most descriptive properties of 33 drones that are available these days and which are suitable for agricultural use ([4] [36]).

The weighting parameters for the selection, evaluation software parameters and selection of the best conditions formulated by drone are as follows:

- Selection of the optimal drone based on data recording

- Selection of the optimal drone based on data collection and data processing (which can be on-line in the drone or using its supplied software, or even in the cloud, regardless of whether the data / recordings are on the drone itself and sent to the cloud, or are processed by the user from the computer after completion of the drone's flight),

- Complete self-service using drones and supporting software: data collection / recording, data processing using BI software, data forwarding intelligent agricultural mechanization,

- Selection of drone based on selective sputtering / fertilization,

- Selection of drone based on data collection / recording and data processing in greenhouses.

The software Expert Choice serves to solve semi-structured and unstructured decision problems. It is based on the AHP method, and Thomas Saaty, the famous author of AHP, participated in its development.

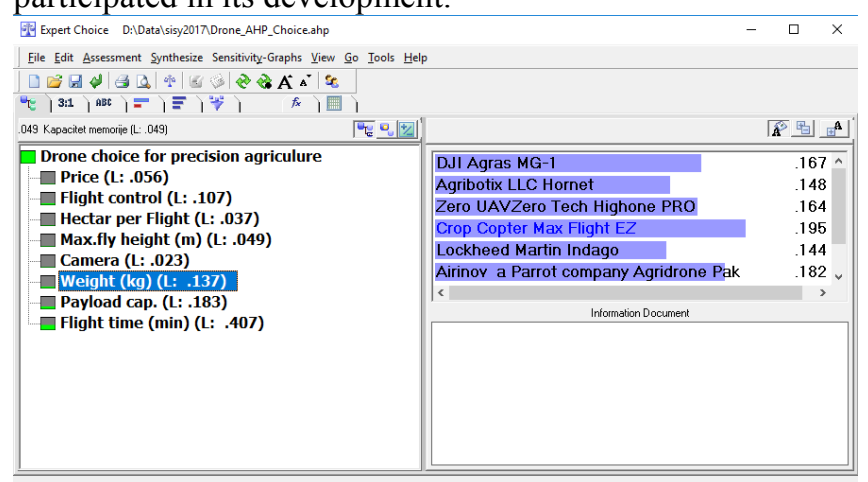

Figure 8. The model view

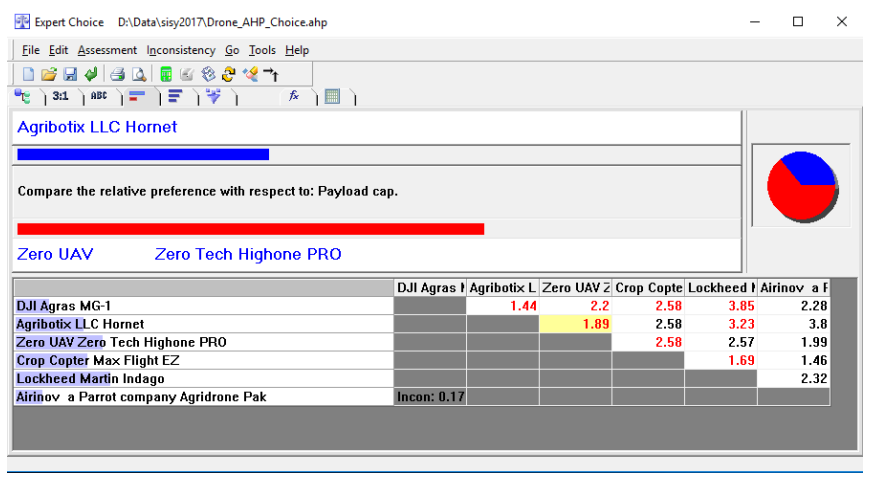

Figure 9. Graphical judgments

After the judgments have been entered, it is possible to request suggestions for reducing the inconsistency. This can be done from any comparison mode.

A synthesis can be done for either the entire model or a portion of the model. From the 'ModelView' (Figure 8), the 'Synthesize, With Respect to Goal' (Figure 9) is selected. The synthesis window will then appear, showing the results (see Figure 10).

The AHP and Expert Choice software engage decisionmakers in structuring a decision into smaller parts, proceeding from the goal to objectives, to sub-objectives, down to the alternative courses of action. Decision-makers then make simple pair-wise comparison judgments throughout the hierarchy to arrive at overall priorities for the alternatives. The decision problem may involve social, political, technical, and economic factors.

\section{CONCLUSION}

The application of UAVs in greenhouses is more specific in comparison to the use of drones in open air. In this context, the drone planes are unsuitable possibly in terms of takeoff, but certainly in terms of landings (look for a large area of land that is not used for other purposes). The dimensions of the UAVs to be used in greenhouses should be smaller and thus, understandably, the weight of the drone must also be less. That is in accordance with the limited dimensions of the real system for monitoring, on the one hand. On the other hand, due to the real demands of farms that the drone must cover. record the entire active portion (the part where the plants are situated) of the greenhouse. Software drone flight control in greenhouses cannot rely on the GPS system for covered/ enclosed space, whereas insufficient accuracy

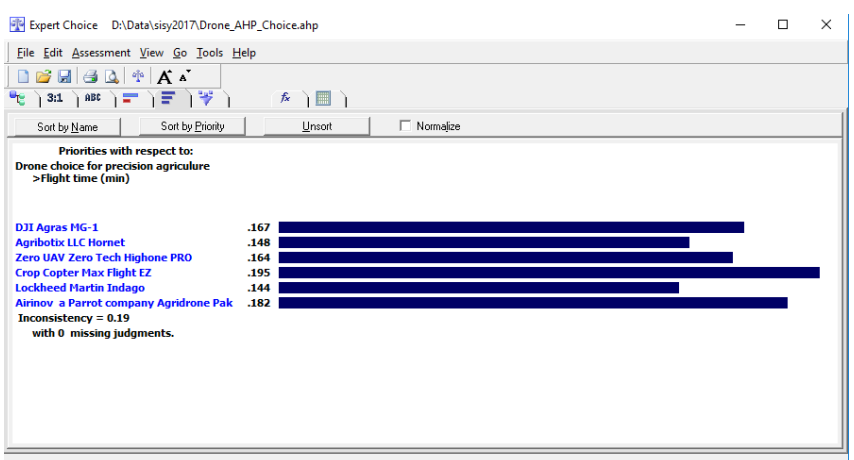

Figure 10. Results view 
of the GPS system does not provide sufficient reliability in determining the exact position of the aircraft. One solution for the management of UAVs indoors is proposed, and presented by a team of authors whose members were the authors of this paper [47]. The required sensors and cameras are in principle no different from those described for drones that are designed for open space. Expert Choice is in this respect intuitive, graphically based and structured in a userfriendly fashion in order to be valuable for conceptual and analytical thinkers, novices and experts. Because the objectives are presented in a hierarchical structure, decisionmakers are able to "drill down" to their level of expertise, and apply judgments to the objectives deemed important in achieving their goals. The best choice based on the model developed using AHP method and Expert choice is Crop Copter Max Flight EZ for the application in precision agriculture.

\section{REFERENCES}

[1] D. Marković, R. Koprivica, U. Pešović, S. Ranđić: "Appliance of IoT in monitoring and controlling of agricultural production", Acta Agriculturae Serbica, Vol. XX, 40 (2015), pp. 145-153.

[2] D. B. Marković, R. M. Pavlović, U. M. Pešović, S. S. Ranđić: "System for monitoring microclimate conditions in greenhouse", Acta Agriculturae Serbica, Vol. XIX, 38(2014), pp 105-1141.

[3] J. Simon: "Optimal microclimatic control strategy using wireless sensor network and mobile measuring agent", Acta Agriculturae Serbica, Vol. XVIII, 36 (2013), pp 111-121.

[4] https://3dr.com/solo-drone/, accessed: 20.02.2017

[5] http://en.aee.com/Drone/, accessed: 20.02.2017

[6] http://www.aerialtechnology.com/, accessed: 28.02.2017

[7] http://ageagle.com/technology/, accessed: 28.02.2017

[8] http://agribotix.com/, accessed: 23.02.2017

[9] http://www.airinov.fr/en/, accessed: 18.03.2017

[10] http://www.asctec.de/en/, accessed: 23.02.2017

[11] http://www.cropcopter.co/, accessed: 17.03.2017

[12] http://www.delair-tech.com/en/packages/, accessed: 28.02.2017

[13] http://www.dji.com/products/phantom, accessed: 06.03.2017

[14] http://www.draganfly.com/uav-helicopter/draganflyercommander/index.php, accessed: 17.03.2017

[15] http://www.ehang.com/ghost2.0.html, accessed: 24.03.2017

[16] http://www.volocopter.com/index.php/en/, accessed: 24.03 .2017

[17] https://hexoplus.com/product/hexo_drone_3d, accessed: 24.02.2017

[18] http://www.honeycombcorp.com/agdrone-uas/, accessed: 28.02.2017

[19] http://www.lockheedmartin.com/us/what-we-do/aerospacedefense/unmanned-systems.html, accessed: 28.02.2017

[20] http://www.nineeagleshop.com/nine-eagles-ufo-quadcopter, accessed: 29.02.2017

[21] http://www.parrot.com/usa/drones/, accessed: 18.03.2017

[22] http://www.precisiondrone.com/product-list/pacesetter/, accessed: 28.02.2017

[23] http://www.precisionhawk.com/, accessed: 21.03.2017

[24] http://prodrone-tech.com/pro.php?lang=en, accessed: 18.03.2017

[25] https://www.sensefly.com/drones/ebee-ag.html, accessed: 21.03 .2017

[26] http://www.trimble.com/Agriculture/UX5.aspx, accessed: 24.03.2017

[27] http://www.walkera.com/, accessed: 24.02.2017

[28] http://xcraft.io/x-plusone-drone/, accessed: 24.03.2017

[29] https://www.yamahamotorsports.com/motorsports/pages/precisionagriculture, accessed: 19.02.2017

[30] http://www.yuneec.com/products, accessed: 12.04.2017

[31] http://www.zerouav.com/en/products/zyhpsy/HighOne1/,

[32] http://uavonic.com/product-categories/products/, accessed:04.03.2017

[33] http://topdronelist.com/drones-for-agriculture/, accessed: 02.03.2017
[34] http://www.lumenier.com/products/multirotors, accessed: 24.03.2017

[35] http://bestdroneforthejob.com/drones-for-work/agriculture-dronebuyers-guide/, accessed: 20.03.2017

[36] J. Young: "Agricultural Drones - An Extensive Overview", Published: $\quad$ February 22, 2016., $\mathrm{http}: / /$ www.droneguru.net/agricultural-drones-an-extensiveoverview/, accessed: 24.04.2017

[37] J. J. Roldán, G. Joossen, D. Sanz, J. del Cerro, A. Barrientos: "MiniUAV Based Sensory System for Measuring Environmental Variables in Greenhouses", Sensors 2015, 15, 3334-3350; doi:10.3390/s150203334, www.mdpi.com/journal/sensors, ISSN $1424-8220$

[38] A. Nixon: "How To Select an Agriculture Drone: An In-Depth Buyer's Guide", Posted on January 12, 2016, http://bestdroneforthejob.com/drones-for-work/agriculture-dronebuyers-guide/, march 24, 2016.

[39] J. Schumpeter: "Digital disruption on the farm", Economist.com/blogs/schumpeter (http://www.economist.com/blogs/schumpeter), May 24, 2014, April $14,2016$.

[40] Drone Industry Insights: "Drone Benchmark Report Sample" (.pdf), Published: December 15, 2015, http://droneii.com/project/dronebenchmark-preview, March 24, 2016.

[41] Drone Industry Insights: "MA-activity-in-the-droneindustry.compressed" (.pdf), Published: February 2, 2016, http://droneii.com/project/drone-ma-activity-from-2011-until-today, March 24, 2016.

[42] Drone Industry Insights: "TOP20 Drone Company Ranking Q1 2016”, Published: February 24, 2016, http://droneii.com/project/top20-drone-company-ranking-report-q12016, accessed: 24.03.2016.

[43] Drone Industry Insights: "FAA-EASA-rule-making-progress" (compressed.pdf), Published: January 7, 2016, http://droneii.com/uavrule-making-what-is-taking-europe-so-long, accessed: 24.03.2016.

[44] E. Delaporte: "An introduction to agricultural UAV imaging systems", Published: October 1, 2015, http://farmprogress.com/storyintroductionagriculturaluavimagingsyst ems0132487, accessed: 17.03.2016

[45] H. G. Coppejans and H. C. Myburgh: "A Primer on Autonomous Aerial Vehicle Design", Sensors, Volume 15 Issue 12, Published: December 2, 2015, http://www.mdpi.com/1424-8220/15/12/29785, 24.03.2016.

[46] Wikipedia: "Normalized_Difference_Vegetation_Index", https://en.wikipedia.org/wiki/Normalized_Difference Vegetation Ind ex, accessed: 15.04.2016.

[47] J. Simon, I. Petkovic, Dj. Petkovic, Á. Petkovics: "Navigation and Applicability of Unmanned Autonomous Aerial Vehicles in Greenhouse Environment", Tehnički vjesnik - Technical Gazette Vol.X, No.X, pp. 1-7, 2016. Under review process

[48] Ericsson: "Connected Vineyards - How the Internet of Things is enhancing the winemaking industry", October, 2015. https://www.ericsson.com/res/docs/2015/iot-connected-vineyards.pdf, accessed: 07.07.2016.

[49] J. Simon: "Concepts of the Internet of Things from the Aspect of the Autonomous Mobile Robots", Interdisciplinary Description of Complex Systems Vol.13 No.1, pp. 34-40, 2015.

[50] J. Simon, Z. Covic: "Data Management of the Automomous Mobile Devices and Internet of Things", ANNALS of Faculty Engineering Hunedoara - International Journal of Engineering Vol. XIII, No. 3, pp. 265-268, 2015.

[51] G. Martinović, J. Simon: "Greenhouse Microclimatic Environment Controlled by a Mobile Measuring Station", Journal of the Royal Netherlands Society for Agricultural Sciences, Vol. 70, No. 1, pp. 6170,2014

[52] I Petkovics, J Trninić, J Đurković, "The role of information technology support in sustainable development", Strategic Management, ISSN: 1821-3448 18 (4), 3-13, 2013

[53] A. Papp, L. Szilassy, J. Sárosi: "Navigation of Differential Drive Mobile Robot on Predefined, Software Designed Path", Recent Innovations in Mechatronics (RIiM), Vol. 3, No. 1-2, ISSN 20649622, pp. 1-5, 2016 